\title{
The good, the bad and the ugly of South African fatal road accidents
}

AUTHORS:
Tanja Verster ${ }^{1}$ iD
Erika Fourie $^{2}$ iD

AFFILIATIONS:

${ }^{1}$ Centre for BMI, North West

University, Potchefstroom,

South Africa

${ }^{2}$ Statistics, North West

University, Potchefstroom,

South Africa

\section{CORRESPONDENCE TO:}

Erika Fourie

EMAIL:

erika.fourie@nwu.ac.za

\section{DATES:}

Received: 14 Dec. 2017

Revised: 29 Jan. 2018

Accepted: 18 Apr. 2018

Published: 30 July 2018

\section{KEYWORDS:}

human factors; road and environmental factors; selfdriving cars; data sources; risk analysis

\section{HOW TO CITE:}

Verster T, Fourie E. The good, the bad and the ugly of South African fatal road accidents. S Afr J Sci. 2018;114(7/8), Art. \#2017-0427, 7 pages. http://dx.doi.org/10.17159/ sajs.2018/20170427

\section{ARTICLE INCLUDES:}

$\times$ Supplementary material

$\times$ Data set

FUNDING:

None

(C) 2018. The Author(s). Published under a Creative Commons Attribution Licence.
We reflect on the good, the bad and the ugly of the fatal accidents occurring on South Africa's roads. The cost of human lives indisputably equates to 'the ugly' and the economic cost of accidents associates with 'the bad'. 'The good' relates to the reduction of both these costs that may result from the entrance of self-driving cars into the South African market as well as awareness campaigns like the Arrive Alive National Road Safety Strategy. The general contribution of this paper is to raise awareness of the effects of accidents, more specifically fatal accidents. Current trends in terms of human factors as well as road and environmental factors involved in the fatal accidents on South African roads are summarised. This paper also serves as a preliminary investigation into possible factors influencing these accidents, which ought to be of interest to a very broad readership, more specifically those focusing on risk analysis, and certainly is of interest to any citizen of South Africa.

\section{Significance:}

- Awareness is raised of the effects of fatal accidents on South African roads.

- Current trends in terms of human factors as well as road and environmental factors on road accidents are reflected upon.

- The futuristic effect of self-driving cars is explored.

\section{Introduction}

The high number of accidents on South African roads not only results in loss of human life with the associated pain, grief and suffering but also has a negative effect on the well-being of South Africans and on South Africa's socio-economic development. The total cost of South African road traffic accidents in 2015 was estimated to be ZAR142.95 billion, which equates to $3.4 \%$ of South Africa's gross domestic product (GDP). The average cost of accidents in similar countries is reported at only $2.2 \%$ of their GDP. ${ }^{1}$ South Africa's economy is not only affected by the direct costs of accidents, but also via the death toll itself as the fatalities most often are the breadwinners of the households, which leaves the rest of the household members financially unattended.

Therefore, the fatal accidents on South African roads pose a threat to all South Africans which, in turn, indicates a need for South Africans - academics and average citizens alike - to be educated about the accidents occurring on South African roads. This need has also been emphasised by the Automobile Association Foundation of South Africa ${ }^{2}$ and the international community (World Health Organization, World Bank and United Nations) in their Decade of Action for Safety from 2010 to 2020 declaration. South Africa joined this initiative by developing its own National Road Safety Strategy 2011-2020. ${ }^{3}$

Awareness campaigns alone may not be sufficient to reduce the number of accidents on South African roads. ${ }^{4}$ One possible solution is to impose compulsory third-party insurance to all motorists. According to John Melville, head of risk services at Santam, a leading South African short-term insurance company, this mandatory third-party vehicle insurance would lower the cost of cover for South African consumers and could also reduce the number of road accidents, because it will bring down the number of damaged vehicles on our roads. ${ }^{5}$

Whether it is for the calculation of general insurance premiums or how the calculation for this third-party insurance premium is done, some risk analyses are required to determine which premium should be charged. Many factors are taken into account when determining the short-term insurance premium. One factor is usually a prediction of the number of accidents; other factors include the type of vehicle driven (how safe is the vehicle) and how often and how far the person drives. ${ }^{6,7}$

The risk posed to all South Africans via the indirect risk of the loss of income (should a fatality be the main income provider of the household) affects life insurance too. The number of fatal accidents also influences the Road Accident Fund. Note that the Road Accident Fund covers personal injury to the third party, but not damage to material possessions such as their vehicle. Third-party insurance usually covers this damage, but up to $35 \%$ of vehicles in South Africa are uninsured..$^{8}$ Again, a risk analysis is required because an increase in fatalities will lead to an increase in claims which will ultimately result in an increase in premiums and increased cost to the Road Accident Fund.

In order for these risk analyses to be conducted, factors that could possibly affect the number or severity of accidents on South African roads need to be determined. Many different industries will benefit from this information. Data sources that contain information regarding these factors also need to be investigated. We undertook an exploratory investigation for those specifically interested in these risk analyses that may be required in future for prediction purposes (such as predicting the number of accidents, the number of claims and the cost of accidents). At the same time, we report some important and interesting findings regarding South African accidents, focusing on fatal accidents, to inform and to raise awareness as a general contribution to the wider audience. 
In 'the good, the bad and the ugly of South African fatal road accidents', the cost of human lives undeniably equates to 'the ugly' and the economic costs associated with these accidents to 'the bad'. 'The good' is addressed by the reduction of both these costs resulting from accident awareness campaigns (e.g. this article), and other initiatives like compulsory third-party insurance, and, in the future, the possible entrance of self-driving cars into the market.

\section{Current situation: Factors influencing accidents}

In order to be able to predict the number of vehicle accidents, one first needs to understand the factors that influence these accidents. Bayam et al. ${ }^{6}$ explain that a vehicle crash is considered to be an interacting system of five factors: (1) driver, (2) vehicle, (3) environmental and geographical conditions, (4) roadway and (5) occupants and other road users. An illustration of Bayam et al.' ${ }^{6}$ five factors is provided in Figure 1. The 'driver' factor relates to personal attributes like the age and gender of the driver. The 'occupants and other road users' factor relates to information regarding the occupants (such as age, gender and other characteristics), the occupants of the other vehicle as well as pedestrians and cyclists or any other road users who had an impact on the accident. These two factors together can also be viewed as the human factors contributing to accidents (indicated by the purple grouping in Figure 1). The 'vehicle' component reflects vehicle type and age (year) of the vehicle. 'Environmental and geographical conditions' comprise weather condition, lighting condition, day and time of day, as well as area type. The 'roadway' factor reflects road attributes such as road condition and road surface. The latter two factors are also referred to as the road and environmental factors (indicated by the green grouping in Figure 1). Information regarding the accident itself, e.g. accident type, number of fatalities and severity, is provided under 'accident', that is, in the middle of the figure.
We set out to explore these factors in relation to fatal accidents. A fatal accident is defined as a crash resulting in the death of one or more persons killed during, immediately after or within 30 days of an accident in which the death was as a direct result of the crash. The persons killed may be the driver of a vehicle involved, passengers of vehicles involved, cyclists or pedestrians. ${ }^{9}$

The data used in this paper refer specifically to fatal accidents that occurred on South African roads during 2015, and were retrieved from a report published by South Africa's Road Traffic Management Corporation, which is the only currently available official accident data. ${ }^{1}$ This information is supplemented with findings from the literature, for example, a project report entitled 'Roads infrastructure policy for South Africa' that was done in collaboration with the Department of Transport, ITS Engineers, Alta Swanepoel \& Associates, and UrbanEcon, released in December 2014. The report notes that the Road Traffic Management Corporation should report and monitor all crashes,${ }^{10}$ not only fatal crashes.

Another example found in the media ${ }^{11}$ stated that the Road Traffic Management Corporation's collection and distribution of data are in chaos and the integrity of the data available is questionable. Specifically, data on non-fatal accidents were corrupted when they were migrated to a new database. ${ }^{11}$ This issue is also raised in the 2016 Road Traffic Management Corporation report in which the importance of quality data on road traffic crashes is emphasised. ${ }^{1}$

Figure 2 provides the breakdown of the number of accidents as well as the cost involved per accident type for the accidents that occurred on South Africa's road network in 2015. It should be noted that fatal crashes constitute only $1.3 \%$ of the number of accidents occurring on South African roads, but $42.4 \%$ of the costs involved.

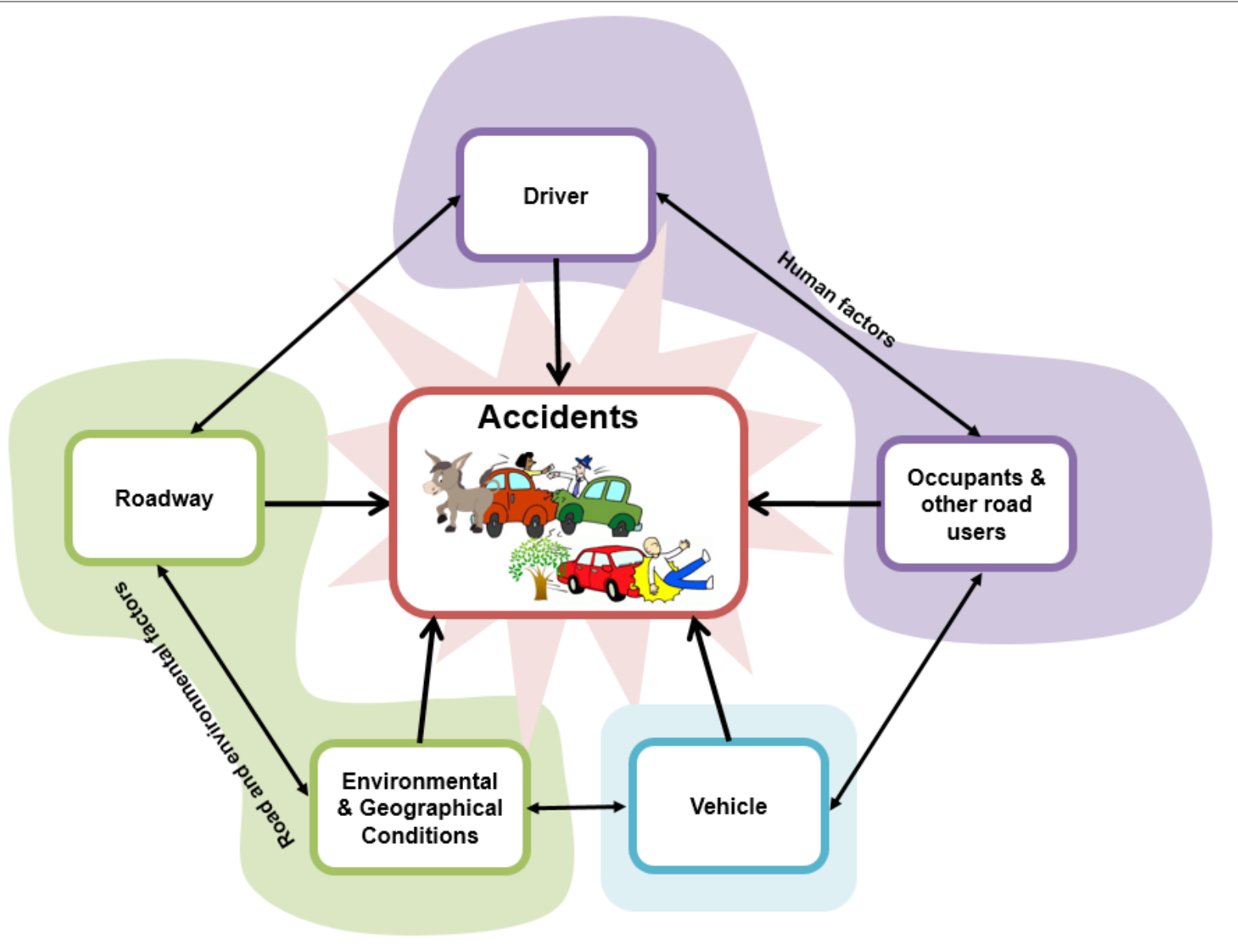

Figure 1: Five factors identified ${ }^{6}$ to cause or interact to cause road accidents. 


\section{Number of accidents per accident type}

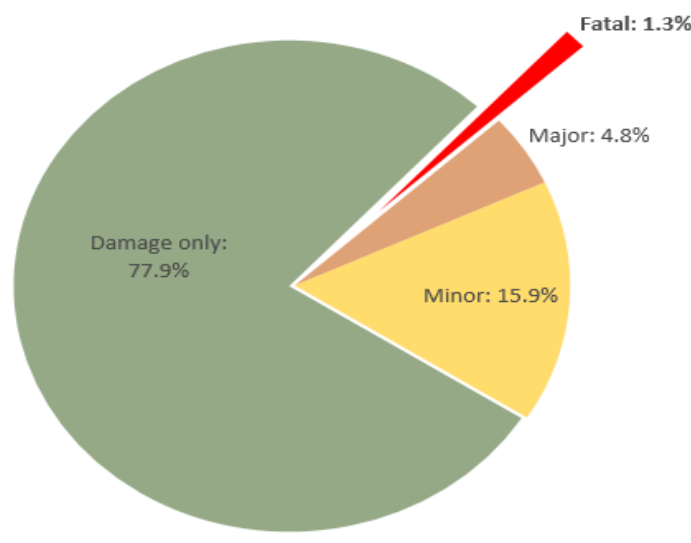

Cost of accidents per accident type

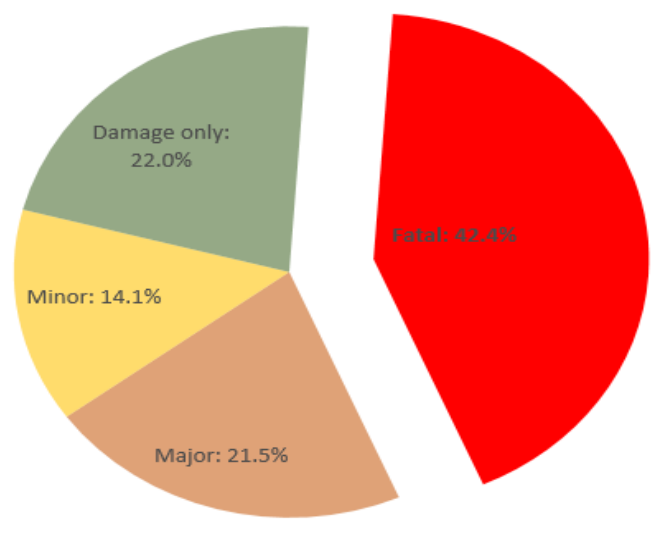

Figure 2: Breakdown of (a) the number of accidents and (b) costs involved per accident type, for the road accidents that occurred in South Africa during 2015.

We focused on fatal accidents because of the more detailed information available. It should be noted that it may take some time before reasonable reporting on non-fatal accidents can be expected.

We first provide some accident information regarding the fatal accidents occurring during 2015 and then discuss each of the five interacting factors grouped into three general contributing factors (as indicated in Figure 1): human factors (i.e. drivers, occupants and other road users), vehicle and road and environmental factors.

\section{Accident information}

As mentioned before, all information is based on fatal accidents. One way to assess the information is to consider the severity of fatal crashes (i.e. the average number of fatalities per crash). Table 1 shows the number of fatal crashes, the number of fatalities and the severity per year, from 2010 to 2015. A total of 10613 fatal accidents occurred from 1 January to 31 December 2015 and resulted in 12944 fatalities. The severity for 2015 is therefore reported at 1.2. Severity can further be explored by considering the day of the week. The highest severity rates are reported for Mondays, Fridays, Saturdays and Sundays, with rates ranging from 1.22 to 1.25 .
Table 1: Accident information for all fatal road accidents reported in 2010 to 2015

\begin{tabular}{c|c|c|c}
\hline \hline Year & Number of fatal crashes & Number of fatalities & Severity \\
\hline 2010 & 10837 & 13967 & 1.3 \\
\hline 2011 & 11228 & 13954 & 1.2 \\
\hline 2012 & 10977 & 13528 & 1.2 \\
\hline 2013 & 10170 & 11844 & 1.2 \\
\hline 2014 & 10367 & 12702 & 1.2 \\
\hline 2015 & 10613 & 12944 & 1.2 \\
\hline
\end{tabular}

Data source: South African Department of Transport ${ }^{9}$

Another way of assessing this type of information is by reviewing the number of fatal crashes as well as the number of fatalities per 10000 vehicles. Figure 3 provides a breakdown of this information per province

\section{Number of crashes and fatalities per 10000 vehicles}

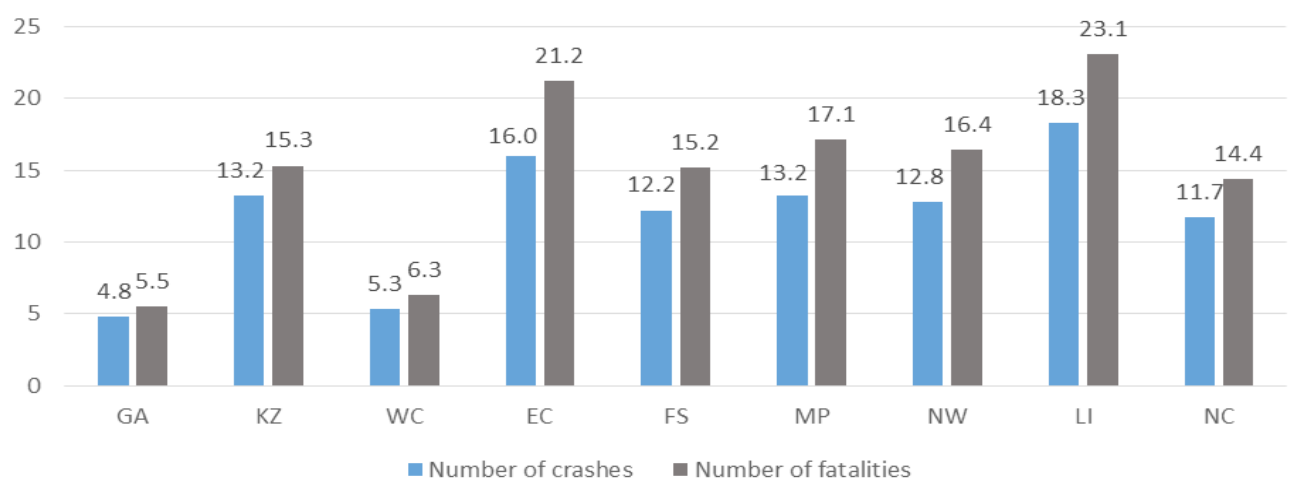

Data source: South African Department of Transport ${ }^{9}$

GA, Gauteng; KZ, KwaZulu-Natal; WC, Western Cape; EC, Eastern Cape; FS, Free State; MP, Mpumalanga; NW, North West; LI, Limpopo; NC, Northern Cape

Figure 3: Number of crashes and fatalities per 10000 vehicles per province. 
for 2015; the blue bars represent the number of fatal crashes and the grey bars represent the number of fatalities. The highest number of fatal crashes per 10000 motorised vehicles was reported for Limpopo Province and the lowest for Gauteng. The same trend is evident for the number of fatalities per 10000 vehicles. The number of crashes per 10000 motorised vehicles for South Africa as a whole is reported at 12 and the number of fatalities at 11 .

\section{Human factors}

Figure 4 gives the distributions of the fatalities per road user type, gender, race and age based on the information provided by the South African Department of Transport. ${ }^{9}$

Of the 12944 fatalities, $27.0 \%$ were drivers and two thirds of these drivers $(66.6 \%)$ were younger than 30 years old. This finding is supported by that of Bédard et al. ${ }^{7}$ who also found that most fatally injured drivers are from this age group. Summala and Mikkola ${ }^{12}$ gave the following reason for this phenomenon: younger drivers tend to avoid and delay taking breaks and also take more deliberate risks than older drivers do.

In addition to the $27.0 \%$ of drivers killed, $32.8 \%$ of the fatalities were passengers and $37.7 \%$ were pedestrians. Male individuals made up $78.0 \%$ and female individuals $22.0 \%$ of the recorded fatalities. This distribution is somewhat different to the national gender distribution of $49 \%$ males and $51 \%$ females. ${ }^{13}$ Based on the known races, the majority (81.4\%) of the fatalities were black individuals. This finding is not surprising, as black people comprise the largest population group in South Africa at $80.7 \%{ }^{13}$ and thus the majority of road users. It can also be seen from Figure 4 that approximately half of the fatalities on South African roads in 2015 were people aged 20-29 years (24.6\%) and $30-39$ years $(24.9 \%)$.

Although pedestrians are amongst the most vulnerable road users, it is alarming that $16.3 \%$ of the pedestrians killed in vehicle accidents were young children (younger than 10 years) and 20.8\% were children 14 years or younger. The Automobile Association Foundation ${ }^{2}$ has also reported that two pedestrians are killed daily by 'vehicle unknown', which means that they have been hit by a vehicle and left to die.

\section{Vehicle}

There are a number of different types of vehicles operating on South African roads, including motor cars (and station wagons), motorcycles, bakkies (or pickups), trucks, buses (both normal and mini), caravans and trailers (both heavy and light).

Almost half $(48.5 \%)$ of the vehicles involved in fatal accidents during 2015 were motor cars (and station wagons), with bakkies second highest (18.4\%). This result is not surprising as these types are also the most registered vehicles on the road at $64.6 \%$ and $22.5 \%$, respectively.

The vehicle type that is third most $(9.0 \%)$ involved in fatal accidents is minibuses. It is reported that 3 of the 36 daily fatalities on South African roads are related to minibus taxis. Public opinion in South Africa is that minibus taxis are unsafe and are being operated in an offensive way. Some of the reasons listed for this phenomenon are that minibus taxis are overloaded in order to increase the number of passengers and are being operated at high speed to reduce travel time. ${ }^{14}$ The most widely publicised, and certainly the most ambitious government intervention in the minibus taxi industry, is the Taxi Recapitalisation Programme. Through this project, the South African government seeks to challenge head-on the problem of an ageing fleet within the South African taxi transportation system. The first objective of this project is the systematic introduction of safe and comfortable vehicles for taxi commuters through a scrapping allowance which acts as an incentive for taxi operators to hand in, on a voluntary basis, their very old vehicles for decommissioning. The second objective is the economic empowerment of the taxi industry through a package of business opportunities that the Recapitalisation Project affords the taxi industry to participate in nationally through

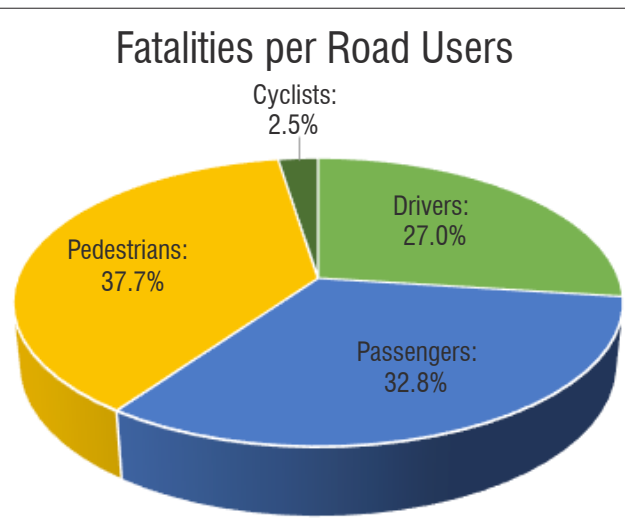

Fatalities per Race

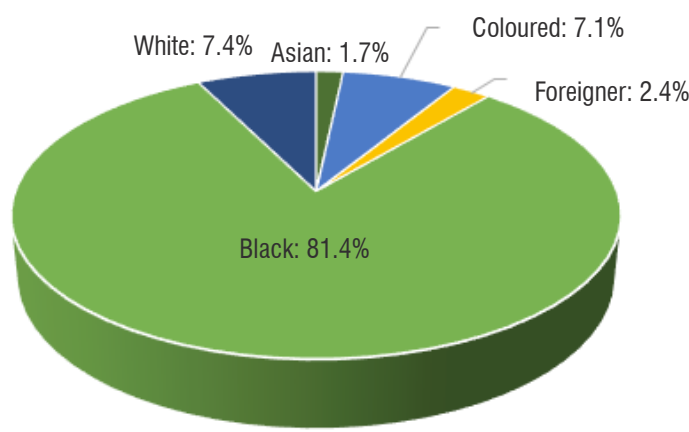

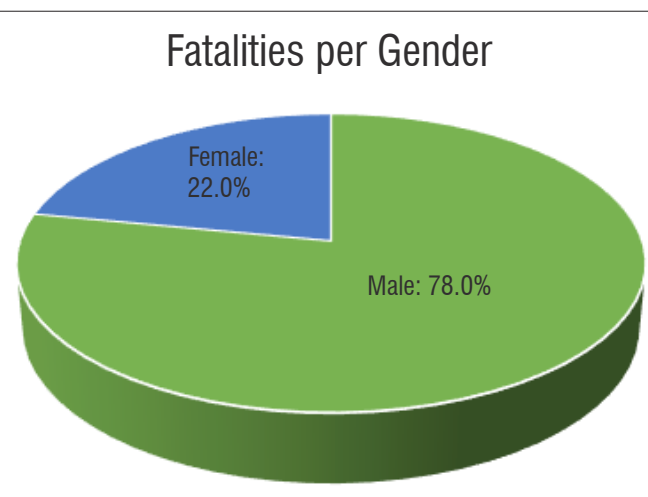

Fatalities per Age

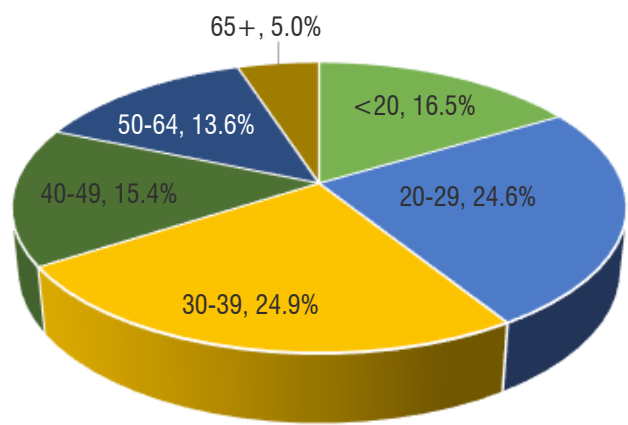

Data source: South African Department of Transport ${ }^{9}$

Figure 4: Distribution of road fatalities per road users, gender, race and age. 
the South African Taxi Council structures as well as at the level of the provincial co-operatives. ${ }^{14}$

The number of unlicenced and/or unroadworthy vehicles on South African roads is alarming - the total number of vehicles falling in this specific category on 31 December 2015 was 1013278.

\section{Road and environmental factors}

One of the most pertinent environmental factors that must be taken into account when assessing accident information is the day of the week on which the accident occurred as well as the month in which the accident occurred. Figure 5 displays the number of fatalities per weekday and per month as reported by the South African Department of Transport. ${ }^{9}$

In total, $60.3 \%$ of the fatal accidents on South Africa's road network occurred on weekends (Fridays, Saturdays and Sundays) and slightly over $40 \%$ of the accidents occurred late afternoon and at night (16:00-22:00). This pattern is commented on in the National Road Safety Strategy 2011-2020 that states that these days are the most dangerous on South African roads. ${ }^{3}$ This strategy document also reports drunk driving as one of the main reasons for the high number of accidents taking place late afternoon and at night.

The month with the highest fatality rate is December at $11.2 \%$, but this result is to be expected as the roads are busiest in December because it is the main holiday period for South Africans. The figures reported for May, July and August are $9.2 \%, 9.2 \%$ and $10.1 \%$, respectively. The lowest rates are reported for January and February, at only $6.0 \%$ and $5.0 \%$; one could argue that people tend to stay at home after their December travels (Figure 5).

The following road and environmental conditions were listed $^{9}$ as reasons for fatal accidents (in descending order):

- $\quad$ Sharp bends

- Poor visibility

- Wet and slippery road surfaces

- Stray or wild animals

- Poor road surfaces

- Poor lighting

- $\quad$ Road works

- Poor and inadequate road markings

- Blind corners

The listed factors do not come as a surprise as various other authors (e.g. Chang and Mannering ${ }^{15}$ and Lord et al. ${ }^{16}$ ) have investigated the effects of road and environmental conditions on road accidents. Only $21 \%$ of South Africa's road network is paved ${ }^{17}$, which is why poor road surfaces, road works as well as poor and inadequate road markings are amongst the reasons listed for fatal accidents.

\section{Summary}

We reviewed the accident information by looking at three general contributing factors: human factors, road and environmental factors and the vehicles involved in the accident. All these factors also influence the risk analysis arena, specifically the short-term insurance and lifeinsurance industry. Figure 6 indicates the percentage of fatal accidents caused by each of the general contributing factors.

Human factors contributed to almost $80 \%$ of the fatal accidents on South African roads, for which $52.5 \%$ of these incidents related to jaywalking (when a pedestrian crosses a roadway where regulations do not permit doing so) and $11.6 \%$ to speeding. Road and environmental conditions contributed to $12.7 \%$ of the accidents, with sharp bends $(22.0 \%)$ and poor visibility $(16.5 \%)$ the main causes. The remaining $7.8 \%$ of the fatal accidents were caused by vehicle factors, with tyres bursting prior to the accident in $71.7 \%$ of the cases (Figure 7).

Should the observations discussed be tracked over time, they could be used as part of the trend analyses required for the previously discussed risk analyses. Even more useful would be trend analyses on all vehicle crashes, and not only the fatal ones. This analysis could be a valuable input in predicting the number of crashes, which in turn could be used as a factor to determine, for example, short-term insurance premiums.

\section{Looking into the future}

The historical fatality rates in South Africa as a result of road accidents paint a dire picture. Some sources even report that road accident fatalities may soon surpass the number of deaths attributed to HIV/Aids. ${ }^{2}$ However, there may be light at the end of the proverbial tunnel as selfdriving cars are expected to enter the market in the near future (see Figure 7 for an illustration of a self-driving car). It is reported that the first self-driving cars might be available from as early as $2018 .{ }^{18}$

A number of benefits are anticipated to emerge from self-driving cars. Those benefits directly relating to road accidents and thus road fatalities are fewer crashes, reduced severity of crashes and improved emergency response times to crashes. Other expected benefits include less traffic congestion, shorter travel times, lower vehicle emissions, better fuel economy and lower insurance rates. ${ }^{20}$

Some of the concerns associated with self-driving cars are that these cars may not be driven as well as those driven by humans and that the cars might not know how to respond in unexpected situations. Other concerns relate to the safety consequences of equipment or system failures and system performance in inclement weather. ${ }^{20}$

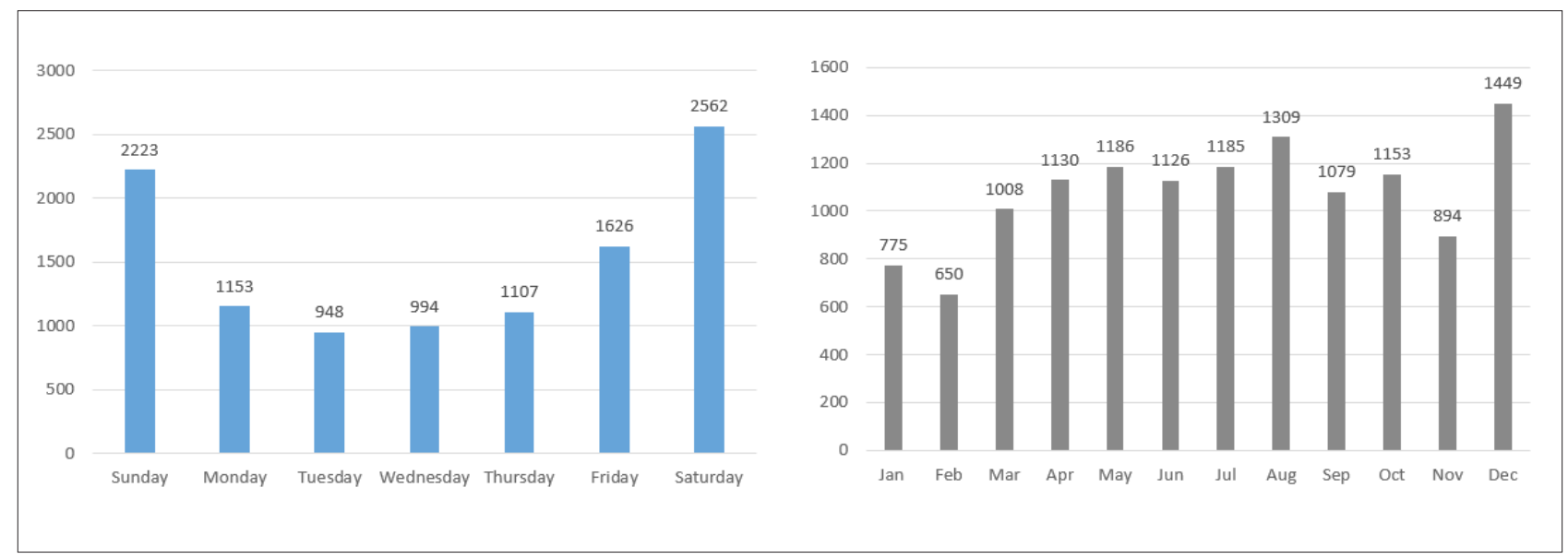

Data source: South African Department of Transport ${ }^{9}$

Figure 5: Number of road fatalities per (a) weekday and (b) month. 


\section{Contribution factors}

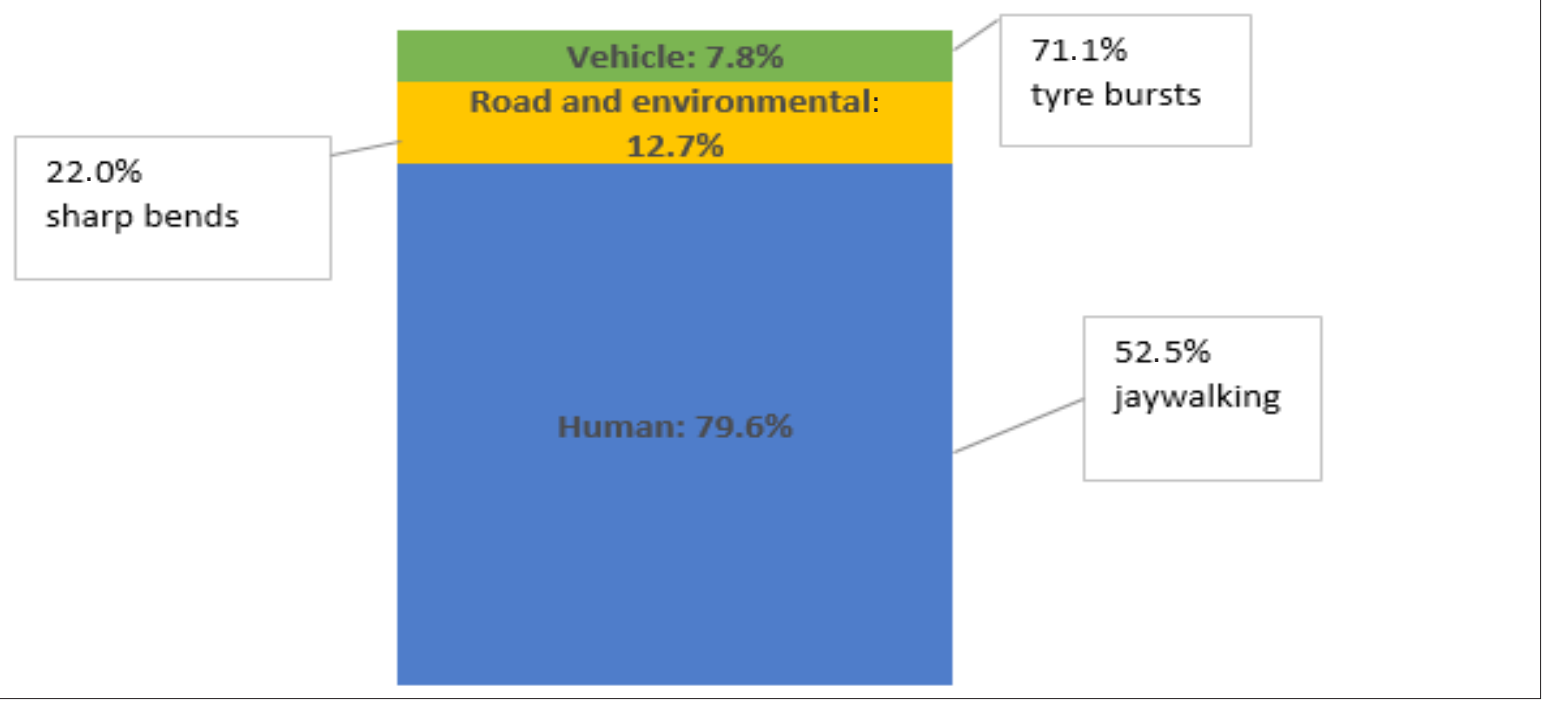

Data source: South African Department of Transport ${ }^{9}$

Figure 6: $\quad$ Graphical summary of the factors contributing towards fatal road accidents.

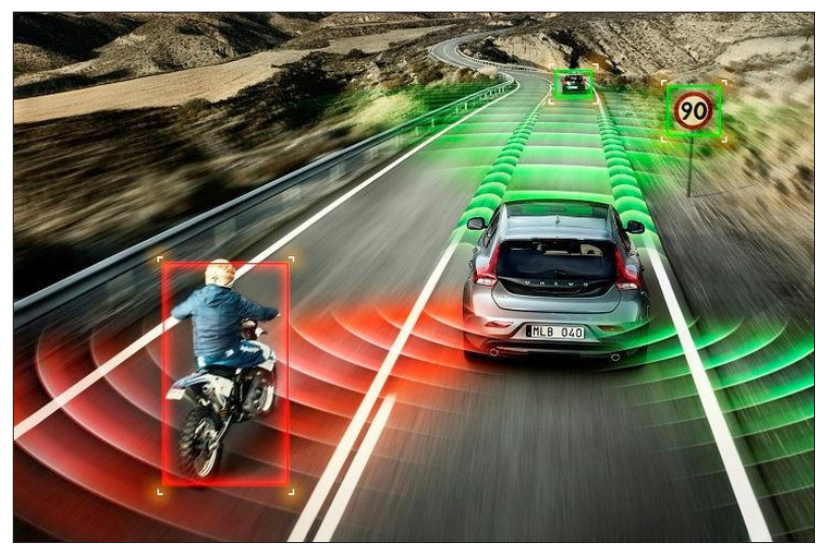

Image: Frank Derks, flickr, CC-BY-2.0

Figure 7: Illustration of a self-driving car. ${ }^{19}$ Green indicates safe zones picked up by the sensors of the self-driving car and red indicates danger zones.

However, it should be noted that the timeline projections for self-driving cars entering the markets are aimed at developed countries. Developing countries like South Africa will have to wait another couple of years. Thus, although South Africans might still miss out on the benefits for another couple of years, hopefully some of the concerns will also have been addressed by the time that self-driving cars enter the South African market.

Another possible 'light' for the future is the impact of the various awareness campaigns. This article serves as one example, but a more formal campaign in South Africa is the Arrive Alive National Road Safety Strategy. The vision of Arrive Alive is 'to develop an effective road safety information portal that will enhance awareness of road safety and save lives' ${ }^{3}$. The World Health Organization has a Decade of Action for Road Safety 2011-2020 Strategy that aims to stabilise the growing number of road traffic crashes and to reduce the number of fatal road traffic crashes by half over a 10-year period. . $^{3,21}$

The possibility of mandatory third-party vehicle insurance might also shed some hope for the future. As mentioned, such insurance could possibly reduce the number of road accidents by reducing the number of damaged vehicles on the roads. ${ }^{5}$

\section{Conclusion and ideas for future research}

A number of different conclusions relating to fatal accidents on South African roads can be made based on the information reported. However, it should be noted that this report contains only information relating to fatal accidents. Although fatal accidents contributed $42.4 \%$ of the costs involved in accidents on South African roads, they equate to only $1.3 \%$ of all the accidents and have quite a unique trend. Thus, focusing on only fatal accidents (because of the lack of available data for other accident types) could result in incorrect conclusions.

Nonetheless, South African citizens should take note that more than 75000 lives have been lost since 2010 as a result of road accidents, of which an alarming $37.7 \%$ were pedestrians. Another noteworthy observation is that slightly more than $40 \%$ of those deceased in 2015 were younger than 30 years of age. The high number of unlicenced and/or unroadworthy vehicles as well as poor road conditions are contributing to South Africa's high road network fatality rate. All of the abovementioned trends could be considered for risk analyses or future predictions, such as the number of accidents and insurance costs.

In 'the good, the bad and the ugly of South African fatal road accidents', the cost of human lives (12 994 lives in 2015) indisputably equates to 'the ugly' and the economic cost of accidents (ZAR142 951 million in 2015) associates with 'the bad'. 'The good', as set out in this paper, relates to the reduction in both of these costs that may be brought forward by the entrance of self-driving cars into the South African market as well as awareness campaigns like Arrive Alive. ${ }^{3}$

Both the cost of human life and the economic effect of road accidents in South Africa paint a shocking picture. This shocking picture emphasises the need to inform South Africans and to raise awareness of the effects of all types of accidents. That said, the South African Department of Transport ${ }^{1}$ has acknowledged the need for a comprehensive road traffic incident database which should include fatal as well as nonfatal accident information. This database should ideally contain the following per accident: the severity, road users' gender and age, day and time of accident, type of road, road condition and location. However, a substantial coordinated effort across a number of sectors will be required to achieve this database.

Once a comprehensive database on all vehicle accidents has been constructed, our analyses can be repeated with a focus on all the different types of accidents, and can include investigation into other possible factors influencing the accident types. From a risk-analysis 
perspective, with specific focus on short-term insurance, a database holding the information of all short-term insurance claims should also be available.

To some extent, such a database already exists and is managed by the South African Insurance Association in conjunction with their key stakeholders, including National Treasury, the Financial Services Board and the Department of Transport as well as all other industries closely related to the short-term insurance industry. ${ }^{8}$ Managed by the South African Insurance Association, the Insurance Data System Committee has steered the collection and management of these crucial data to the point at which all contributing members have submitted their historical files and are submitting daily claims updates to the database. However, the voluntary submission of company statistics remains a challenge. ${ }^{8}$ Alternatively, this central database could also be managed by an objective and independent institution like a university, in which case the data would also be more accessible for future research projects.

\section{Authors' contributions}

Both authors contributed equally to the conceptualisation of the study, data collection and writing of the manuscript.

\section{References}

1. South African Department of Transport. Cost of crashes in South Africa. Research and development report. Tshwane: Road Traffic Management Corporation; 2016. Available from: http://www.rtmc.co.za/images/media/ Cost $\% 20$ of\%20Crashes\%20in\%20South\%20Africa\%20-\%20RTMC\%20-\%20 September\%202016.pdf

2. AA Foundation. The impact of speed on South African road fatalities [document on the Internet]. c2003 [cited 2017 Jan 05]: Available from: http:// aa-upgrade.ensight.ws/upload/documents/general/aa-foundation-speed.pdf

3. Arrive Alive. Decade of action and arrive alive. National road safety strategy 2011-2020. Bloemfontein: Arrive Alive; 2011. Available from: https:// www.arrivealive.co.za/documents/Road\%20Safety\%20Strategy\%20for\%20 South\%20Africa\%202011.pdf

4. Barry C. South Africa needs a third party insurance programme. FleetWatch. 2017 July 20 [cited 2018 Jan 20]: Available from: https://fleetwatch.co.za/ south-africa-needs-a-third-party-insurance-programme/

5. Hesse M. 3rd-party cover for your car. IOL Personal Finance. 2015 July 04 [cited 2018 Jan 25]. Available from: https://www.iol.co.za/personalfinance/3rd-party-cover-for-your-car-1880315

6. Bayam E, Liebowitz J, Agresti W. Older drivers and accidents: A meta-analysis and data mining application on traffic data. Expert Syst Appl. 2005;29:598629. https://doi.org/10.1016/j.eswa.2005.04.025

7. Bédard M, Guyatt GH, Stones MJ, Hirdes JP. The independent contribution of driver, crash, and vehicle characteristics to driver fatalities. Accid Anal Prev. 2002;3:717-727. https://doi.org/10.1016/S0001-4575(01)00072-0

8. South African Insurance Association. Annual review 2016. Metamorphosis. Johannesburg: South African Insurance Association; 2016. Available from: https://www.saia.co.za/annual-review-2016.pdf
9. South African Department of Transport. Road traffic report. Calendar: 1 January - 31 December 2015. Tshwane: Road Traffic Management Corporation; 2015. Available from: http://www.rtmc.co.za/rtmc1/Docs/ JanDec2015.pdf

10. South African Department of Transport. Roads infrastructure policy for South Africa: Policy framework. Pretoria: ITS Engineers (Pty) Ltd; 2014. Available from: http://www.swartland.org.za/media/docs/2015/Documents/Services/ Salga/Roads\%20Infrastructure\%20Policy\%20-\%20Policy\%20Framework.pdf

11. Joseph R. Who are South Africa's worst drivers? The truth doesn't lie in the data. Africa Check. 2013 July 04 [cited 2018 Jan 12]. Available from: https:// africacheck.org/2013/07/04/who-are-south-africas-worst-drivers-the-truthisnt-in-the-data/

12. Summala $\mathrm{H}$, Mikkola T. Fatal accidents among car and truck drivers: Effect of fatigue, age and alcohol consumption. Hum Factors. 1994;36(2):315-326. https://doi.org/10.1177/001872089403600211

13. Statistics South Africa (StatsSA). Community survey 2016. Statistical release P0301. Pretoria: StatsSA; 2016. Available from: http://cs2016.statssa.gov. za/wp-content/uploads/2016/07/NT-30-06-2016-RELEASE-for-CS-2016Statistical-releas_1-July-2016.pdf

14. Arrive Alive. Minibus taxis and road safety [webpage on the Internet]. c2017 [cited 2017 Jan 23]. Available from: https://www.arrivealive.co.za/MinibusTaxis-and-Road-Safety

15. Chang LY, Mannering F. Analysis of injury severity and vehicle occupancy in truck- and non-truck-involved accidents. Accid Anal Prev. 1999;31(5):579592. https://doi.org/10.1016/S0001-4575(99)00014-7

16. Lord D, Washington SP, Ivan JP. Poisson, Poisson-gamma and zero-inflated regression models of motor vehicle crashes: Balancing statistical fit and theory. Accid Anal Prev. 2005;37(1):35-46. https://doi.org/10.1016/j. aap.2004.02.004

17. National Treasury. Local government budgets and expenditure review: 2006/07 - 2012/13. Pretoria: National Treasury; 2011. Available from: http:// www.treasury.gov.za/publications/igfr/2011/lg/02.\%202011\%20LGBER\%20 -\%20Final\%20-\%2013\%20Sept\%202011\%20(renumbered).pdf

18. Kalogianni $A$. The next 10 years in car tech will make the last 30 look like just a warm-up. Digital Trends. 2016 January 12 [cited 2017 Jan 05]. Available from: http://www.digitaltrends.com/cars/the-future-of-car-tech-a-10-yeartimeline/

19. Posky M. Saying what's popular: Suppliers claim automakers are overselling the future of 'mobility'. The Truth about Cars. 2017 August 03. Available from: http://www.thetruthaboutcars.com/2017/08/suppliers-claiming-automakersoversold-future-mobility/

20. Schoettle B, Sivak M. A survey of public opinion about autonomous and selfdriving vehicles in the U.S., the U.K., and Australia. Ann Arbor, MI: University of Michigan Transportation and Research Institute; 2014. Available from: https://deepblue.lib.umich.edu/bitstream/handle/2027.42/108384/103024. pdf? sequence $=1$ \&isAllowed $=y$

21. World Health Organization (WHO). Global plan for the decade of road safety action 2011-2020. Geneva: WHO; 2011. Available from: http://www.who.int/ roadsafety/decade of action/plan/plan english.pdf 